\title{
COMMISSIONING OF A 20 K HELIUM REFRIGERATION SYSTEM FOR NASA-JSC CHAMBER-A
}

\author{
J. Homan ${ }^{\mathrm{a}}$, R. Redman ${ }^{\mathrm{a}}$, V. Ganni ${ }^{\mathrm{b}}$, A. Sidi-Yekhlef ${ }^{\mathrm{b}}$, P. Knudsen ${ }^{\mathrm{b}}$, R. Norton ${ }^{\mathrm{b}}$, J.

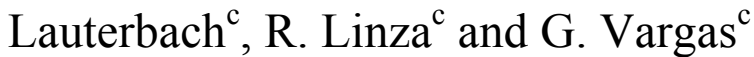 \\ ${ }^{a}$ NASA, Johnson Space Center, Houston TX 77058 \\ ${ }^{b}$ Thomas Jefferson National Accelerator Facility (JLab), Newport News, VA 23606 \\ ${ }^{c}$ Jacobs Technology, Engineering and Science Group-JSC, Houston, TX 77058
}

\begin{abstract}
A new $20 \mathrm{~K}$ helium refrigerator installed at NASA Johnson Space Center's Space Environment Simulation Laboratory (SESL) was successfully commissioned and tested in 2012. The refrigerator is used to create a deep space environment within SESL's Chamber A to perform ground testing of the James Webb Space Telescope (JWST). The chamber previously and currently still has helium cryo-pumping panels (CPP) and liquid nitrogen shrouds used to create low earth orbit environments. Now with the new refrigerator and new helium shrouds the chamber can create a deep space environment. The process design, system analysis, specification development, and commissioning oversight were performed by the cryogenics department at Jefferson Lab, while the contracts and system installation was performed by the ESC group at JSC. Commissioning data indicate an inverse coefficient of performance better than $70 \mathrm{~W} / \mathrm{W}$ for a 18 $\mathrm{kW}$ load at $20 \mathrm{~K}$ (accounting for liquid nitrogen pre-cooling power) that remains essentially constant down to one third of this load. Even at 10 percent of the maximum capacity, the performance is better than $150 \mathrm{~W} / \mathrm{W}$ at $20 \mathrm{~K}$. The refrigerator exceeded all design goals and demonstrated the ability to support a wide load range from $10 \mathrm{~kW}$ at $15 \mathrm{~K}$ to $100 \mathrm{~kW}$ at $100 \mathrm{~K}$. The refrigerator is capable of operating at any load temperature from $15 \mathrm{~K}$ to ambient with tight temperature stability. The new shroud ( 36 tons of aluminum) can be cooled from room temperature to $20 \mathrm{~K}$ in 24 hours. This paper will outline the process design and commissioning results.
\end{abstract}

Keywords: Large Scale Refrigerator, Floating Pressure, Space Environment Testing, NASA.

PACS: $89.20 . \mathrm{Bb}$

\section{INTRODUCTION}

NASA JSC's Chamber A has recently undergone extensive modifications to prepare for testing the James Webb Space Telescope (JWST) [1]. One of the major changes was the addition of a $20 \mathrm{~K}$ refrigerator and new thermal shrouds to help create a deep space environment within the chamber. The refrigerator was a collaborative effort between NASA JSC engineers and contractors, Jefferson Lab, and private industrial partners. The planning of this refrigerator was presented $[2,3]$.

\section{Project Planning}

The exact requirements for the refrigerator were not known at the beginning of the project, but several key requirements were established. Namely, the ability to quickly cool a large structure to below $100 \mathrm{~K}$, handle a variable load and support a projected steady state refrigeration load of $11.5 \mathrm{~kW}$ at $20 \mathrm{~K}$ with a thermal stability of $0.25 \mathrm{~K}$. The refrigeration system was designed to support a variable load from $100 \mathrm{~kW}$ at $100 \mathrm{~K}$ to $12.5 \mathrm{~kW}$ at 20 K, utilizing the Ganni Cycle Floating Pressure Process.

As a demonstration of the Floating Pressure Process, NASA JSC with JLab upgraded two $3.5 \mathrm{~kW}$ existing $20 \mathrm{~K}$ refrigerators in the JSC facility [3]. JLab designed the process for the new refrigerator system, selected all the major components to be used in the system and divided the system into sub-systems for competitive procurement. JLab developed the detailed specifications for each sub-system based on cost effective industrial practices. 


\section{Procurement of the Sub Systems}

The first sub-system procured was the $20 \mathrm{~K}$ cold box (CBX-3) from Linde Process Systems, Tulsa, Oklahoma [2]. The specification included detailed specifications for process design, sizing of heat exchangers, valves, instrumentation and controls, control philosophy and the preliminary cold box layout with all the components in the cold box.

The second sub-system procured was the helium compressor (CMP-3) from Salof Engineering, New Braunfels, Texas. The specification included detailed design drawings, specifications for process and component design including the Howden compressor, oil cooler and helium gas (after) cooler heat exchangers, valves, instrumentation and controls, control philosophy and the component layout. As allowed by the specification, Salof chose to implement some modifications to the JLab build to print drawings that they felt were necessary to meet the system guarantee required by NASA.

The other sub-systems procured per JLAB specification include the final oil removal system, compressor gas management skid, warm distribution piping, bake-out heater, and helium bulk gas unload station and storage tank. Chart Industries provided the bare and vacuum jacketed (VJ) interconnecting field piping, in accordance with detailed design drawings provided by JLab. NASA, JLab and the Jacobs Engineers conducted all the necessary design reviews and over saw the production of the sub-systems at various industrial partners' locations.

\section{INSTALLATION, COMMISSIONING AND TESTING}

Jacobs Engineering ESC (JSC's Engineering and Science Contract), provided the contract support, field coordination of the sub-system installation and the integration of the total system. They also provided the technical support for system operations. JLab provided the commissioning planning, direction and oversight to the NASA contractors and to the equipment sub-system vendors.

The system implemented the Ganni Cycle Floating Pressure Process control, described in [3-5] to automatically adjust the system capacity to the actual load at the required return temperature from the load. JLab and the equipment vendors provided the training to operate each subsystem and the overall system to NASA engineers and their contractors.

\section{Compressor System Tests}

The compressor system successfully completed its acceptance test in March of 2013 with NASA, JLab, Jacobs and Salof all providing support. Initial testing proved all performance points for refrigeration system could be met. Figures 1 and 2 depict the measured isothermal performance vs. pressure ratio for various discharge pressures and built-in volume ratios (BVR's). 


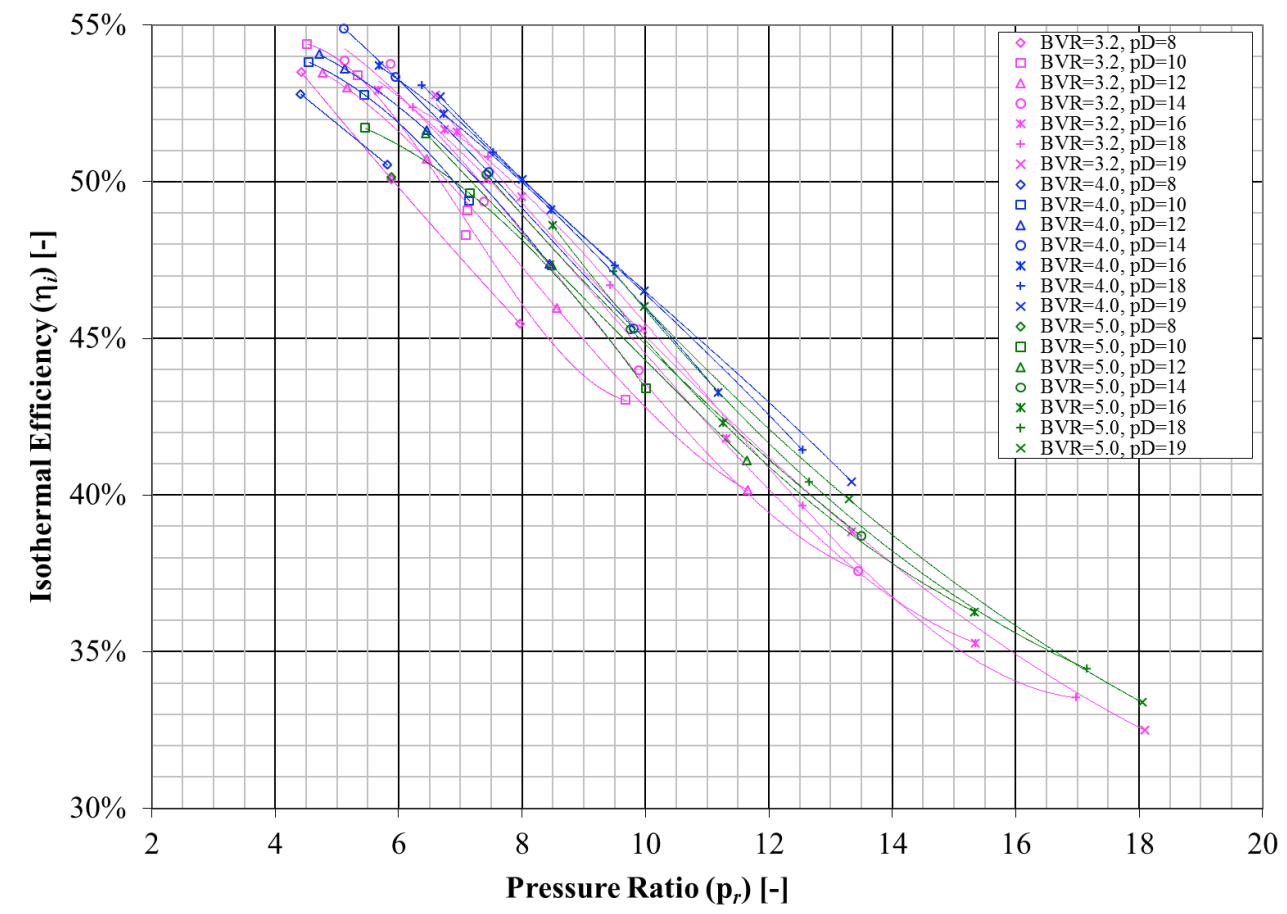

FIGURE 1. Compressor isothermal performance vs. pressure ratio for various discharge pressures and built-in volume ratios (BVR's)' curves color grouped by BVR

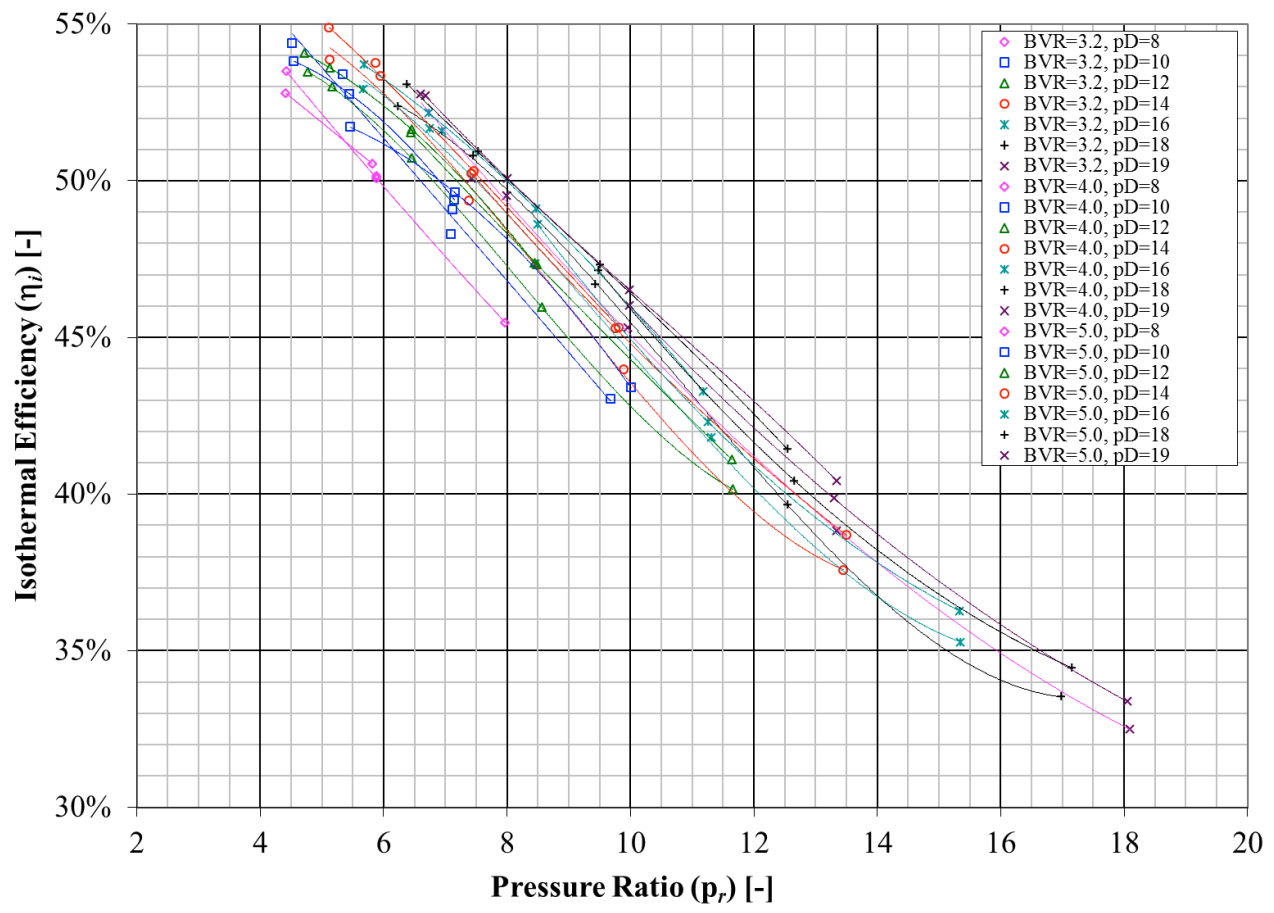

FIGURE 2. Compressor isothermal performance vs. pressure ratio for various discharge pressures and built-in volume ratios (BVR's)' curves color grouped by discharge pressure 


\section{Refrigeration System Tests}

The cold box design and the control philosophy were presented in $[2,5]$. The cold box is equipped with two identical turbines to support a $100 \mathrm{~kW}$ load at $100 \mathrm{~K}$, to aid the cool down and as a redundancy for improved availability of the system.

The CMP-3 and the CBX-3 with all the other sub-systems like final oil removal system, compressor gas management, and helium inventory management system are tested as an integrated system using a heater internally located in CBX-3 to simulate the load. The required load temperature is manually set and the load is varied as desired (at the selected temperature). The system was allowed to adjust itself to the optimal operating conditions. Figures 3 and 4 show the tested performance of the helium refrigeration system which demonstrated an unprecedented load range of $11.2 \mathrm{~kW}$ at $15 \mathrm{~K}$ to $118 \mathrm{~kW}$ at $100 \mathrm{~K}$. The system is also able to automatically support any loads at $20 \mathrm{~K}$ from $30 \%$ to $100 \%$ at practically constant efficiency without any manual interventions and with temperature stability better than $\pm 0.1 \mathrm{~K}$.

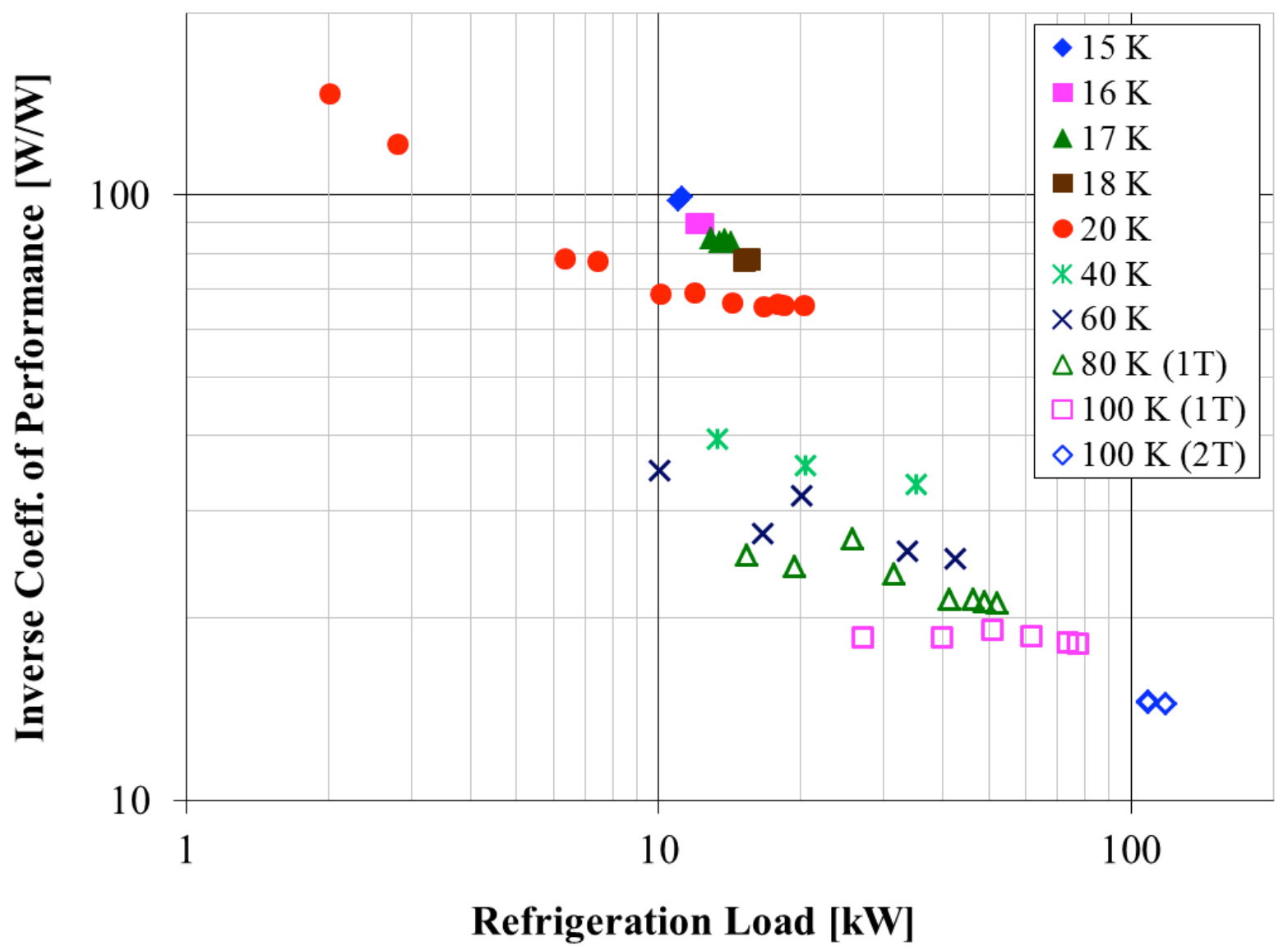

FIGURE 3. Refrigerator performance at various loads and load temperatures 


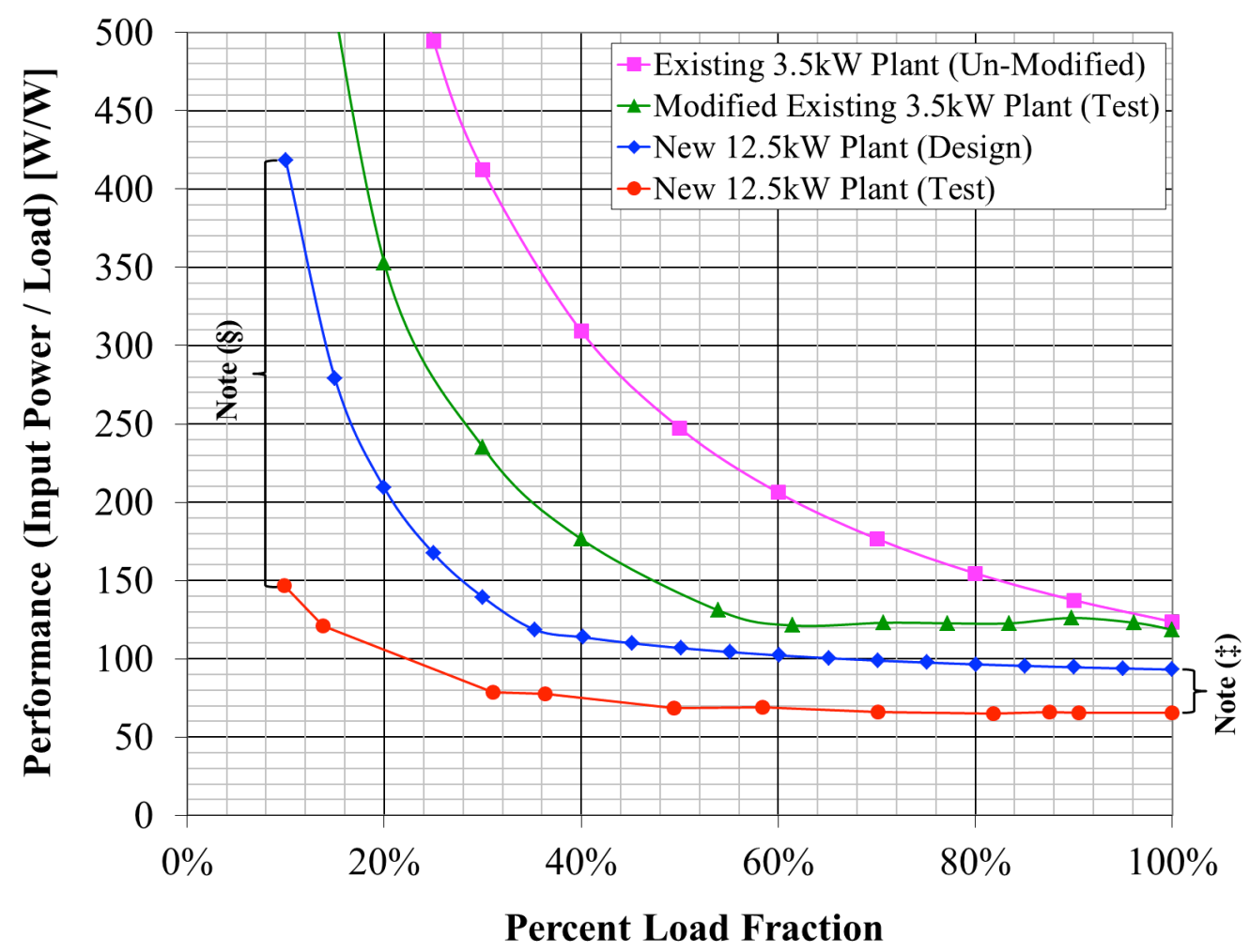

Notes: (§) Offset due to actual expander efficiency higher than minimum required by refrigerator specification (so as to not restrict competition in the bid process).

(†) Increased offset due to using the slide valve at low loads during commissioning (which is more efficient) than adding heat.

FIGURE 4. Refrigerator performance at $20 \mathrm{~K}$ as compared to design and $3.5 \mathrm{~kW}$ refrigerator

\section{Required Chamber Modes of Operations and Functional Test Results}

The following is a list of required chamber modes of operation for the helium refrigeration system, the project goals and results achieved during the August 2012 functional test.

a. Bake-out: The goal of the helium system was to get the helium shrouds to an average of $330 \pm 5 \mathrm{~K}$. During the functional test an average temperature of $332 \mathrm{~K}$ was achieved with the potential for a higher average temperature.

b. Cool-down Time: The requirement for cooling the new helium shroud ( 23 metric tons of aluminum) to less than $20 \mathrm{~K}$ was 48 hours. In the first operation this was achieved in about 30 hours.

c. Cool-down temperature: The requirement was to achieve a temperature below $20 \mathrm{~K}$ "as low as possible". The goal for the refrigerator was to cool below $15 \mathrm{~K}$, which was achieved.

d. Measure static load ("clean dry empty chamber"): This was measured to be approximately $\sim 2.5 \mathrm{~kW}$ at $20 \mathrm{~K}$

e. Measure load with helium backfill: The chamber pressure was raised to $10^{-3} \mathrm{mbar}$ with helium. This added approximately $5 \mathrm{~kW}$ of additional load (i.e., total $7.5 \mathrm{~kW}$ load on the refrigerator)

f. Control warm-up to allow slow release of condensed air: A goal, but not a firm requirement, was to control the refrigerator to warm up slowly and hold when a change in chamber pressure was noticed. This was accomplished successfully by warming the shrouds to $26 \mathrm{~K}$, holding for over an hour, and observing a release of nitrogen into the chamber background. This was also used to warm-up the helium shrouds to above $170 \mathrm{~K}$ and hold while the liquid nitrogen shrouds were kept at $80 \mathrm{~K}$. This would be used to help drive and collect water vapor during chamber testing. 
In addition, the system was found/verified to:

i. Have no (detectable) loss of helium

ii. Maintain a temperature stability of $\pm 0.1 \mathrm{~K}$ at $20 \mathrm{~K}$, which exceeded the goal of $\pm 0.25 \mathrm{~K}$.

iii. Have an inverse coefficient of performance of less than $66 \mathrm{~W} / \mathrm{W}$ at peak operation, an increase of less than $20 \%$ in input power (for the same load) at $31 \%$ of the peak load.

iv. Have a very wide and continuous load range; e.g.,
(a) $11 \mathrm{~kW}$ at $15 \mathrm{~K}$
(b) $20.4 \mathrm{~kW}$ at $20 \mathrm{~K}$
(c) $35.1 \mathrm{~kW}$ at $40 \mathrm{~K}$
(d) $42.6 \mathrm{~kW}$ at $60 \mathrm{~K}$
(e) $51.9 \mathrm{~kW}$ at $80 \mathrm{~K}$ (single turbine)
(f) $73.2 \mathrm{~kW}$ at $100 \mathrm{~K}$ (single turbine)
(g) $118 \mathrm{~kW}$ at $100 \mathrm{~K}$ (two turbine)

v. System flexibility in piping design to operate any compressor with any coldbox for existing and new thermal shrouds

Figure 5 shows the shroud bake-out history during the August 2012 functional test. Figure 6 shows the shroud cool-down and warm-up history during that test. Figure 7 depicts the control screen for the helium shrouds (i.e., the shroud color changes from 'red' to 'blue' as it cools).

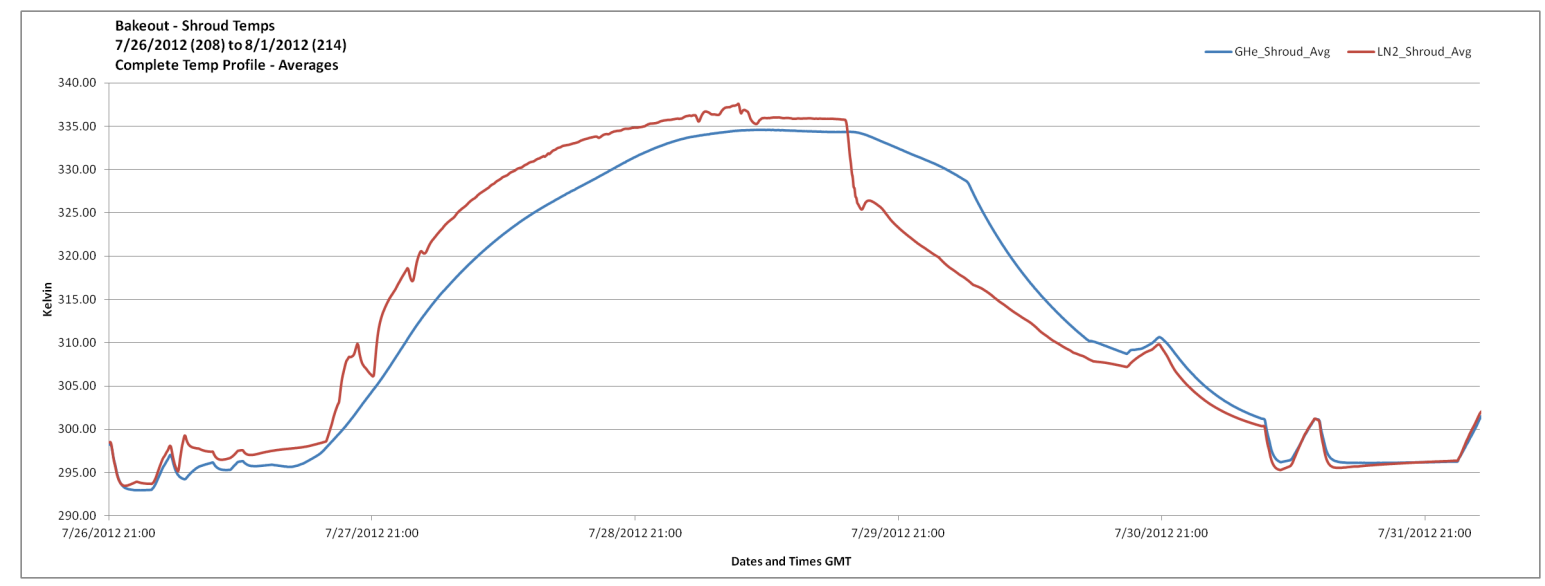

FIGURE 5. Shroud bake-out history during August 2012 functional test

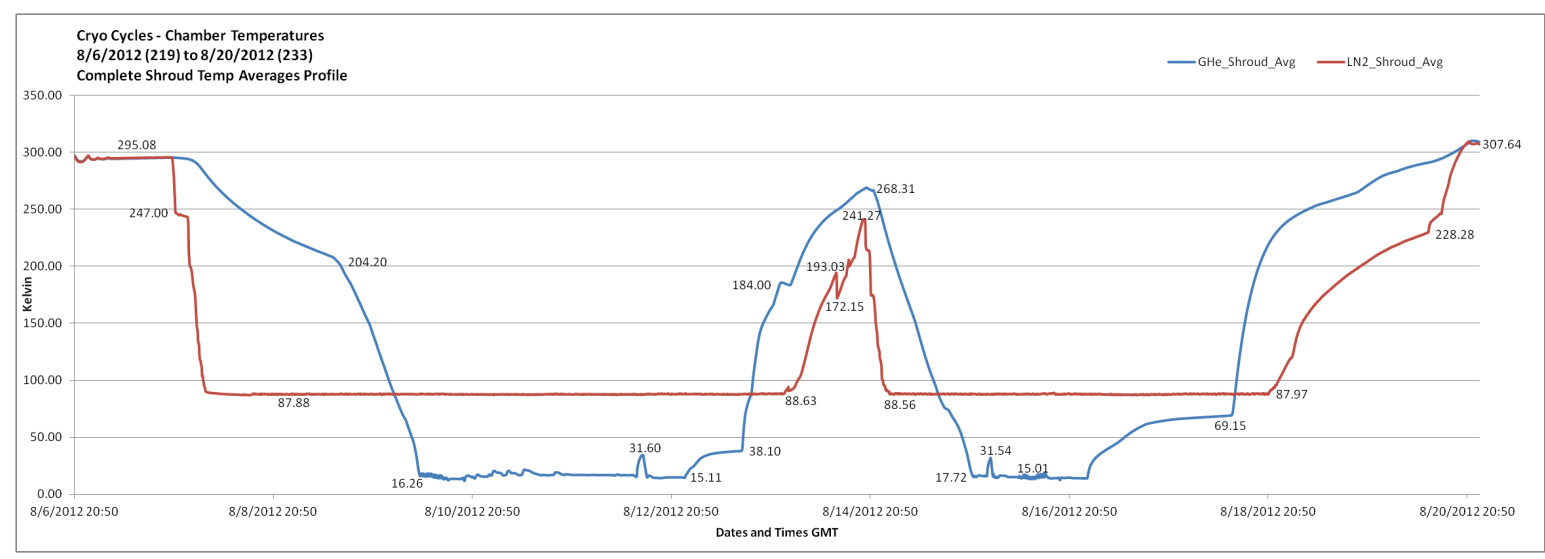

FIGURE 6. Shroud cool-down and warm-up temperature history during August 2012 functional test 


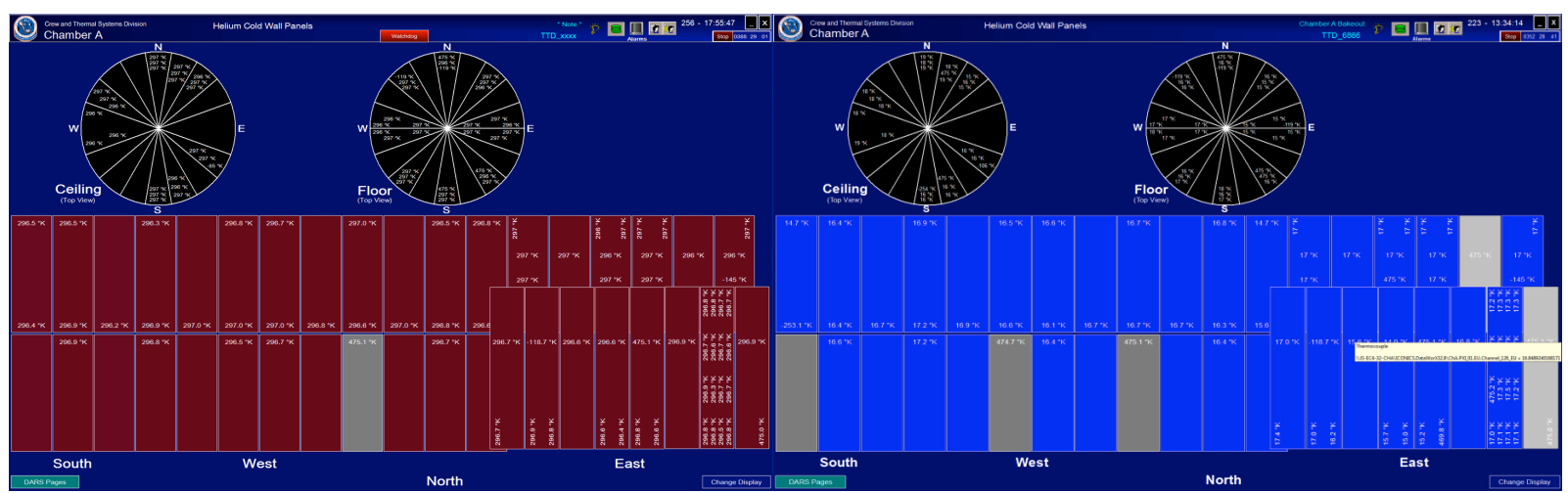

FIGURE 7. Helium shroud temperature display screen

\section{SUMMARY}

The helium refrigeration system has been designed to meet all the requirements and desires for the JWST test program, having demonstrated the flexibility to handle a demanding initial cool down capacity, an accelerated cool down of the mirrors and other components of the telescope after the chamber is cooled, allow operation of the chamber at varying temperature levels while maintaining the steady state loads and temperature stability with very high efficiency in all these modes using the floating pressure process. It is presently undergoing three month continuous operation endurance test and completed 70 days and will complete the week after the conference.

\section{ACKNOWLEDGMENTS}

This work is a co-operative result of NASA JSC, Jefferson Lab, Jacobs Engineering, Hamilton Sundstrand, many industrial partners who supplied the equipment and colleagues of the above institutions.

\section{REFERENCES}

1. Information on JWST can be found at http://jwst.nasa.gov/index.html

2. P. Arnold, L. Decker, D. Howe, J. Urbin, J. Homan, C Reis, J. Creel, V. Ganni, P. Knudsen, A. Sidi-Yekhlef, "Large Scale Refrigeration Plant for Ground Testing the James Webb Telescope at NASA Johnson Space Center" in Advances Cryogenic Engineering 55B, 2010, pp. 1080-1086.

3. J. Homan, V. Ganni, A. Sidi-Yekhlef, J. Creel, R. Norton, R. Linza, G. Vargas, J. Lauterbach, J. Urbin, D. Howe, "Floating Pressure Conversion and Equipment Upgrades of Two 3.5kW 20-K Helium Refrigerators" in Advances Cryogenic Engineering 55B, 2010, pp. 1072-1079.

4. V. Ganni, "Optimal Design and Operation of Helium Refrigeration Systems," in Proceedings of the 23rd Particle Accelerator Conference (PAC09), Vancouver, BC, Canada, WE4RA101, May 2009.

5. V. Ganni, P. Knudsen, "Optimal Design and Operation of Helium Refrigeration Systems Using the Ganni Cycle" in Advances in Cryogenic Engineering 55B, 2010, pp. 1057-1071. 